\title{
Molecular mechanisms of polymyxin resistance and detection of $m$ cr genes
}

\author{
Patrik Mlynarcik, Milan Kolar
}

\begin{abstract}
Antibiotic resistance is an ever-increasing global problem. Major commercial antibiotics often fail to fight common bacteria, and some pathogens have become multi-resistant. Polymyxins are potent bactericidal antibiotics against gram-negative bacteria. Known resistance to polymyxin includes intrinsic, mutational and adaptive mechanisms, with the recently described horizontally acquired resistance mechanisms. In this review, we present several strategies for bacteria to develop enhanced resistance to polymyxins, focusing on changes in the outer membrane, efflux and other resistance determinants. Better understanding of the genes involved in polymyxin resistance may pave the way for the development of new and effective antimicrobial agents. We also report novel in silico tested primers for PCR assay that may be able distinguish colistin-resistant isolates carrying the plasmid-encoded $\mathrm{mcr}$ genes and will assist in combating the spread of colistin resistance in bacteria.
\end{abstract}

Key words: polymyxin, colistin, resistance, LPS

Received: May 21, 2018; Accepted: October 26, 2018; Available online: November 15, 2018 https://doi.org/10.5507/bp.2018.070

Department of Microbiology, Faculty of Medicine and Dentistry, Palacky University Olomouc, 77515 Olomouc, Czech Republic Corresponding author: Patrik Mlynarcik, e-mail: patrik.mlynarcik@upol.cz

\section{INTRODUCTION}

Constantly increasing antibiotic resistance is a global health problem. In particular, serious infections caused by multi-resistant bacteria, especially carbapenem-resistant bacteria, as well as the lack of new antibiotics against gram-negative pathogens, have led to the revival of older antibiotics. In this context, the use of colistin has been reintroduced, especially in infections caused by multidrug-resistant gram-negative bacteria. Unfortunately, increased and disproportionate use of colistin has led to the emergence of colistin-resistant bacteria worldwide. However, the presence of resistant bacteria to colistin may also occur without any prior exposure to colistin ${ }^{1}$. Polymyxins represent a family of antimicrobial cyclic oligopeptides produced by the gram-positive organism Bacillus polymyxa. However, only polymyxin B and polymyxin E (colistin) are suitable for clinical use. They act both on the outer and on the cytoplasmic membrane, resulting in loss of integrity in the membrane. Recently, alternative and less characterized mechanisms of action of polymyxins, as well as some bacterial resistance to these antibiotics have been described ${ }^{2}$. The reviewed literature shows a number of published studies on polymyxin resistance. In this review, we cover current knowledge on polymyxin resistance mechanisms in bacteria with regard to changes in the outer membrane and efflux. However, we also focus on other polymyxin resistance determinants with unclear and unknown function which may prove to be important components of resistance. Further, we tried to design primers for the detection of all previously described colistin-resistance genes ( $m c r-1$ to -7$)$ and their variants.

\section{Overview of polymyxin resistance}

Known resistance mechanisms include intrinsic, mutational and adaptive, but recently horizontally acquired resistance has also been described ${ }^{3-5}$. The major polymyxin resistance mechanisms include (i) alteration of the lipopolysaccharide (LPS) moiety, resulting in a reduction of the net LPS negative charge; (ii) mutations in genes; (iii) increased drug efflux; (iv) reduced porin pathway, (v) formation of capsules and (vi) enzymatic inactivation of antibiotic (colistin). However, other mechanisms of polymyxin resistance have also been described (e.g. antioxidative defense mechanisms, hyper-vesiculation). In the following section we will try to summarize the current state of knowledge concerning polymyxin resistance.

\section{Electrostatic repulsion of polymyxins by modification of cell surface}

The most common polymyxin resistance mechanisms in different pathogenic bacteria are associated with modification the phosphate groups of lipid A with amine substituents, such as 4-amino-4-deoxy-L-arabinose (L-Ara4N) and phosphoethanolamine (PEtn), which are regulated by the two-component systems (TCSs) PhoP/PhoQ and PmrA/PmrB regulatory system. The addition of L-Ara4N and PEtn reduces the net negative charge of bacterial surface and limits its interaction with polymyxins, which ultimately results in increased resistance to polymyxins ${ }^{6,7}$. It has been reported that cross-talk between the PhoPQ and PmrAB systems exists in Salmonella enterica and is mediated by the protein PmrD which is induced by phosphorylated PhoP (ref. ${ }^{8}$ ). Recently, it was observed that missense mutations in $\mathrm{CrrB}$ is linked to colistin resistance in Klebsiella pneumoniae isolates. In this context, $\mathrm{CrrC}$ was required to activate PmrAB and thereby connecting 
Table 1. Sequences of primers used for PCR for detection of $m c r$ genes and their variants.

\begin{tabular}{|c|c|c|c|c|c|c|}
\hline Primer name & Sequence $\left(5^{\prime} \text { to } 3^{\prime} \text { direction }\right)^{\mathrm{a}}$ & Target & $\begin{array}{l}\text { Length } \\
\text { (bases) }\end{array}$ & $\begin{array}{c}\text { Amplicon } \\
\text { size }\end{array}$ & $\begin{array}{l}\mathrm{Tm} \\
\left({ }^{\circ} \mathrm{C}\right) \\
\end{array}$ & Ref. \\
\hline MCR-1F & GTCGATACCGCCAAATACC & MCR-1/-2/-6 & 19 & $559 \mathrm{bp}$ & 52 & This study \\
\hline MCR-1R & GTTCTTTTGGTGCAAAGGC & & 19 & & & \\
\hline MCR-2F & TGCATGTTYTCCAAYATGGGG & MCR-3/-7 & 21 & $416 \mathrm{bp}$ & 54 & This study \\
\hline MCR-2R & CGRATGGTRTTGTCATAGGTGTT & & 23 & & & \\
\hline MCR-3F & GATCCGAAGCTGTGTTCTG & MCR-4 & 19 & $380 \mathrm{bp}$ & 52 & This study \\
\hline MCR-3R & GGCGCACCATGTAAATACA & & 19 & & & \\
\hline MCR-4F & GCTGYAAAGGCGTCTGYGA & MCR-3/-5 & 19 & $382 \mathrm{bp}$ & 54 & This study \\
\hline MCR-4R & TGATCGGARACGTASAGCA & & 19 & & & \\
\hline
\end{tabular}

${ }^{\mathrm{a}}$ For degenerate primers: $\mathrm{R}=\mathrm{A}$ or $\mathrm{G} ; \mathrm{S}=\mathrm{G}$ or $\mathrm{C} ; \mathrm{Y}=\mathrm{C}$ or $\mathrm{T}$.

crr $A B$ and $p m r A B$ TCSs (ref. ${ }^{9}$ ). Further, other TCSs like ParRS, CprRS and ColRS are also implicated in the regulation of lipid A modification enzymes ${ }^{4,10-12}$. The spectrum of genes controlled by these TCSs are shown in Table 1 and Figure 1. Another mechanism for repulsion of cationic polymyxins is D-Ala modification of lipoteichoic acid. Briefly, GraXSR-promoted polymyxin B resistance in Staphylococcus aureus is related to the increased net positive surface charge due to the induction of genes dlt$A B C D$ associated with addition of D-Ala to teichoic acids $^{13}$. The same mechanism of resistance to polymyxin $B$ involving surface modification through the incorporation of D-alanine into an outer membrane (OM) has also been described in Bordetella pertussis, Streptococcus gordonii and Listeria monocytogenes by regulating the dra and dlt operon $^{14-16}$. Additionally, in the case of S. gordonii and Streptococcus agalactiae, involvement of two-component regulatory system response regulators LiaSR and CiaR in polymyxin B and to the cationic antimicrobial peptides (CAMP) resistance respectively have been found, and their effect on the expression of $d l t$ has been demonstrated $^{16-18}$.

Other mechanisms have been described as associated with modification of the cell surface leading to electrostatic repulsion of antimicrobial peptides. This refers to (1) deacylation of lipid A, (2) phosphorylation and dephosphorylation of LPS, (3) glycylation of lipid A, (4) activation of LPS-modifying operon by mutations in twocomponent system, (5) repression of PhoPQ system, (6) L-Lys modification of cell membrane phoshpatidylglycerol, (7) addition of amide-linked acyl chains in the lipid A and (8) glucosamine modification. All these findings are carefully described in Trimble et al. ${ }^{2}$. It is also worth mentioning that a ferrous iron-binding protein, outer membrane protein $(\mathrm{Omb})$ with unclear biological role, caused alterations in the bacterial surface charge that decreased affinity to antimicrobial peptides and increased resistance to polymyxin B in $S$. enterica ${ }^{19}$.

Recently, plasmid-mediated resistance to polymyxin has been reported in a number of animal and human isolates of E. coli and $K$. pneumoniae, and the gene responsible for this phenotype was identified as $m c r-1$ (ref. ${ }^{5}$ ). For more detail, please see reference ${ }^{2}$. Up to now, at least seven different $\mathrm{mcr}$ genes and their variants have been identified. In response to the growing number of $\mathrm{mcr}$ genes and their variants, we have tried to design the primers used for the detection of all previously described types of the respective gene. The nucleotide sequences of $\mathrm{mcr}$ genes were downloaded from the GenBank database (accession numbers CP010516, KP347127, KU886144, KY807920, KY807921, KY924928, LT598652, MF176240, MG267386, MF176239, MF176240, MF495680, MF543359, MF598076, MF598077, MF598078, MF598079, MF598080, MF598564, MG459156, MG459157, MG581979, MG822663, MG822664, MG822665, NQCO01000074) and were aligned (data not shown) using Geneious Pro 8 (Biomatters) to identify highly homologous regions suitable for designing primers. The proposed but untested primers may be used for detection of $m c r-1$ to -7 genes and their variants. The primer sequences and calculated lengths of the corresponding amplicons are listed in Table 1.

\section{Membrane fluidity/permeability changes}

Other mechanisms related to surface structural changes, acylation and deacylation of lipid A, influences resistance to different types of antimicrobial peptides. These changes have been shown to alter the properties of the outer-membrane permeability barrier. It was shown that activation of PhoPQ system in $K$. pneumoniae with polymyxin B stimulates PagP ( $\operatorname{crc} A$ in $E$. coli) involved in acylation of lipid A (ref. ${ }^{20}$ ). In addition, PagP-like gene, rcp in Legionella pneumophila, also conferred resistance to polymyxin B (ref. ${ }^{21}$ ). In Vibrio cholerae, K. pneumoniae, Escherichia coli and Salmonella Typhimurium, the acylation of lipid A has been shown to be regulated by $\operatorname{lp} x M$ (formally $m s b B$ or waaN). Inactivation of these genes resulted in a lack of L-Ara4N modification and in a significant decrease in polymyxin resistance ${ }^{22-25}$. Furthermore, other genes such as Bmul_2133 and Bmul_2134 have been shown to contribute to polymyxin B resistance in Burkholderia multivorans through alterations in the OM permeability ${ }^{26}$. It has been proposed that Bmul proteins appear to confer polymyxin B resistance by the mechanism of hopanoid (analogues of eukaryotic sterols) biosynthesis involved in maintaining membrane fluidity and permeability ${ }^{27}$. Moreover, it was observed that genes involved in staphyloxanthin (virulence factor) biosynthesis confer resistance to polymyxin B in $S$. aureus. The resistance to polymyxin B in this case is derived from its sta- 
Table 2. Strategies used by bacteria to achieve resistance to polymyxins.

\begin{tabular}{|c|c|c|c|c|}
\hline \multicolumn{2}{|c|}{ Resistance mechanisms } & \multirow{2}{*}{$\begin{array}{l}\text { Genes/determinants involved } \\
\text { pmrAB, pmrD, phoPQ, parRS, mcr }\end{array}$} & \multirow{2}{*}{$\begin{array}{l}\text { Bacteria } \\
\text { Escherichia coli, Salmonella } \\
\text { enterica, Pseudomonas aeruginosa }\end{array}$} & \multirow{2}{*}{$\begin{array}{l}\text { Ref. } \\
4-8,10-12\end{array}$} \\
\hline $\begin{array}{l}\text { Electrostatic } \\
\text { repulsion }\end{array}$ & $\begin{array}{l}\text { L-Ara } 4 \mathrm{~N} \text { and PEtn } \\
\text { modification of } \\
\text { lipid A }\end{array}$ & & & \\
\hline & $\begin{array}{l}\text { Activation of LPS- } \\
\text { modifying operon by } \\
\text { mutations in two- } \\
\text { component system }\end{array}$ & $\operatorname{crr} B(\operatorname{crr} C)$ & Klebsiella pneumoniae & 9 \\
\hline & $\begin{array}{l}\text { D-Ala modification } \\
\text { of lipoteichoic acid }\end{array}$ & graXSR, dra/dlt operon, liaSR, ciaR & $\begin{array}{l}\text { Staphylococcus aureus, Bordetella } \\
\text { pertussis, Streptococcus gordonii, } \\
\text { Listeria monocytogenes, Group B } \\
\text { Streptococcus }\end{array}$ & $13-18$ \\
\hline & Unclear & outer membrane protein $(\mathrm{Omb})$ & Salmonella enterica & 19 \\
\hline \multirow[t]{2}{*}{$\begin{array}{l}\text { Membrane } \\
\text { fluidity/ } \\
\text { permeability }\end{array}$} & Acylation of lipid A & pagP, lpxM, rcp & $\begin{array}{l}\text { Vibrio cholerae, Klebsiella } \\
\text { pneumoniae, Escherichia coli, } \\
\text { Salmonella enterica, Legionella } \\
\text { pneumophila }\end{array}$ & $20-25$ \\
\hline & $\begin{array}{l}\text { putative hopanoid } \\
\text { and staphyloxanthin } \\
\text { biosynthesis }\end{array}$ & $\begin{array}{l}\text { Bmul_2133/Bmul_2134, genes involved in } \\
\text { staphyloxanthin biosynthesis }\end{array}$ & $\begin{array}{l}\text { Pseudomonas aeruginosa, } \\
\text { Burkholderia multivorans, } \\
\text { Staphylococcus aureus }\end{array}$ & 26,28 \\
\hline
\end{tabular}

Surface and Capsule production siaD, cps operon, ompA, kpnEF, phoPQ, rcs membrane remodelling

\section{Alterations} in membrane composition
virB, $\operatorname{suh} B_{B c}$, bvrRS, epsC-N, cgh, vacJ, waaL, rfbA, ompW, micF, pilMNOPQ operon, parRS, rsmA, bveA, ydeI (omdA), ompD (nmpC), ygiW (visP), ompF, rcs
Alterations of cas 9, tracrRNA, scaRNA, Lol, TolQRA membrane integrity LOS and LPS modifications
spgM, pgm, hldA, hldD, oprH, cj1136, waaF, lgtF, galT, cstII, galU, lic1, lic2A, lpsA, lgtF, ops X, firA, lpxO
Neisseria meningitidis, Klebsiella 20, 29-32, pneumoniae, Salmonella enterica 34

Brucella ovis, Salmonella enterica, 10, 12, 33, Brucella melitensis, Burkholderia 34, 37-47, cenocepacia, Vibrio cholerae, $\quad 49,50$, Brucella abortus, Klebsiella $\quad 52-54$ pneumoniae, Pseudomonas aeruginosa, Neisseria meningitidis, Brucella melitensis

Francisella novicida, Acinetobacter 55, 56 baumannii

Stenotrophomonas maltophilia, 57-65, 68, Vibrio fischeri, Burkholderia $\quad 69,71$ cenocepacia, Eschericha coli, Pseudomonas aeruginosa, Salmonella Typhimurium, Campylobacter jejuni,

Haemophilus influenzae Acinetobacter baumannii $\quad 72,73$

\begin{tabular}{lll} 
& Loss of LPS & lpxACD, lptD \\
\hline $\begin{array}{l}\text { Efflux and } \\
\text { transport }\end{array}$ & Efflux & Mex pumps, AdeABC, HlyD \\
& & \\
& Transport & trk $A$
\end{tabular}

Other polymyxin resistance $\quad$ bacA, sip, $p b s$, type IV pili, $v c$ genes, yieM, sodC,
determinants with known, unclear $\operatorname{sodB}$, katA, pilB, yjdB/pmrC/pagB/pmrF, PA1199, and unknown function
PA2583, PA5548, PA2928, eraR, $w b p Z$, PA4541, PA1938, pgm, surA, tolB, gnd, PA0401, pyrB, pdxB, sucC, tpiA, aroB, pyrD, mpl, hypothetical protein (rmlD homolog), ampR, lptC, amgS, galU, lptC, wapR, ssg, cgt, kdnA/kdnB, fopC, pstA/C/S, ebsA, topA, fts $H, g d p P$, fabT, yfmH, agaS, $\operatorname{manL} / \mathrm{N}$, clpX, deoB, hpt, tilS, gmk, nanH, guaA, nupP, ptsI, luxR, fba, ugtL, virK, mig-14, pgtE, asmA, pbgP, $m g l B$, glpQ-like, feoC, hflc, pitA, rpoE, BCAL2831, тисD, lyt $B, h p n J$, genes encoding putrescine, yceI, yejABEF operon, spy, zraP, срxP, micA, rybB, pgmA, grxD, low $\mathrm{pH}$, extracellular DNA, lack of magnesium/ phosphate/iron ions, JSG945, JSG946, JSG948, YPTB0331-0332-0333 and other genes

\begin{tabular}{|c|c|}
\hline $\begin{array}{l}\text { Pseudomonas aeruginosa, } \\
\text { Acinetobacter baumannii }\end{array}$ & 74,55 \\
\hline Vibrio vulnificus & 75 \\
\hline $\begin{array}{l}\text { Brucella ovis, Thermus } \\
\text { thermophilus, Acinetobacter } \\
\text { baumannii, Klebsiella } \\
\text { pneumoniae, Saccharomyces } \\
\text { cerevisiae, Pseudomonas } \\
\text { aeruginosa, Vibrio cholerae, } \\
\text { Escherichia coli, Staphylococcus } \\
\text { aureus, Burkholderia cenocepacia, } \\
\text { Salmonella enterica, Group } \\
\text { B Streptococcus, Brucella suis, } \\
\text { Helicobacter pylori, Shewanella } \\
\text { oneidensis, Francisella novicida, } \\
\text { Streptococcus pyogenes, Yersinia } \\
\text { pestis, Proteus mirabilis, Yersinia } \\
\text { pseudotuberculosis, Yersinia }\end{array}$ & $\begin{array}{l}3,26,28, \\
38,43,49, \\
61,77-87, \\
89,90,92, \\
93,95,96, \\
98-104, \\
106-111, \\
113-117\end{array}$ \\
\hline
\end{tabular}




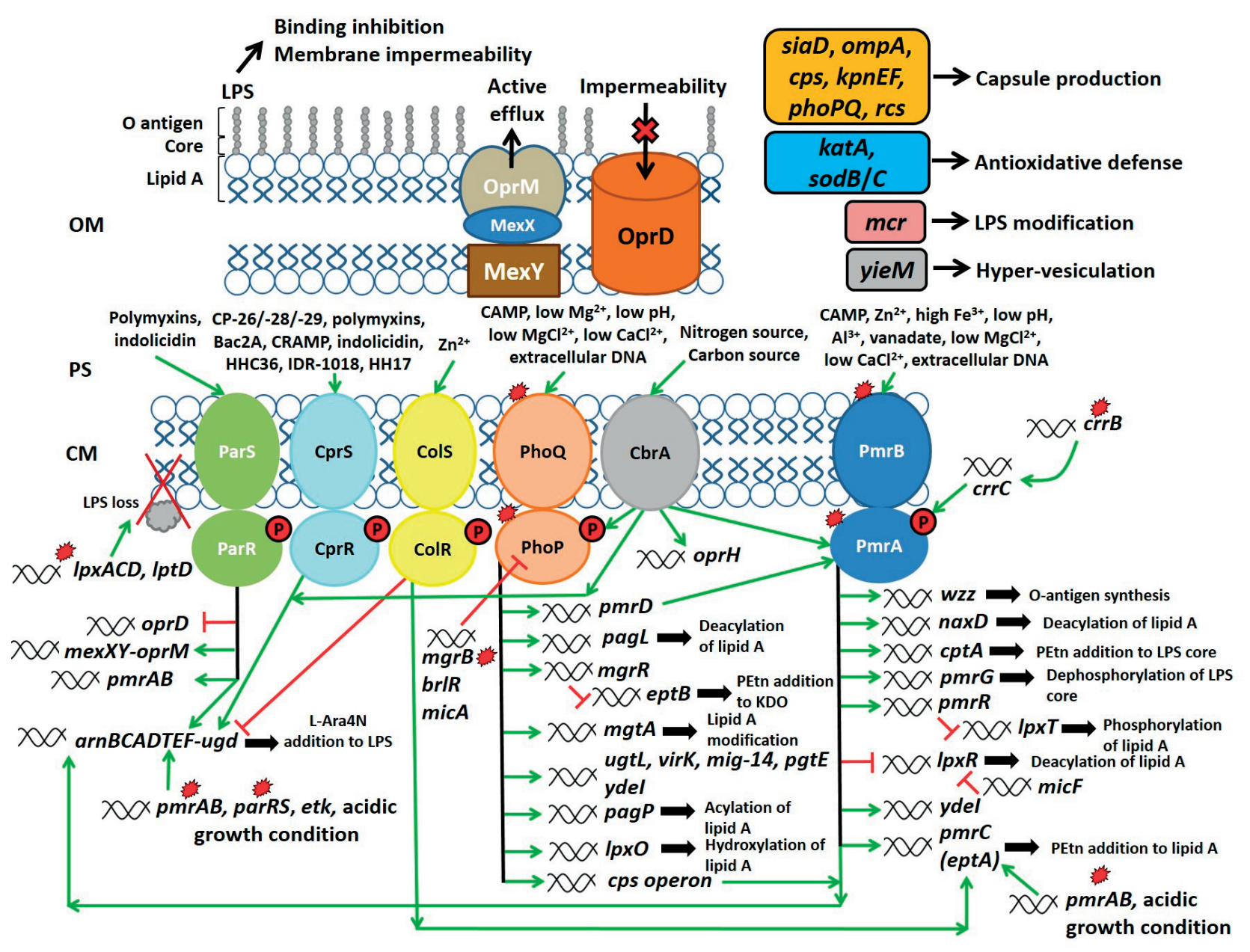

Fig. 1. Proposed polymyxin resistance mechanisms in bacteria. PhoP-PhoQ, PmrA-PmrB, ColR-ColS, CprS-CprR, ParS-ParR and CbrA-CbrB two-component systems confer bacterial resistance to polymyxin. Diagram of gram-negative cellular envelope, which shows typical inner and outer double layer separated by a periplasm (OM, outer membrane; PS, periplasmic space; CM, cytoplasmic membrane). The outer layer of the outer membrane contains a lipopolysaccharide (LPS), which is anchored to the membrane by the LPS lipid A. The inner layer of the outer membrane and also the entire inner membrane are composed only of phospholipids and the two bilayers can contain a variety of different types of membrane proteins. The figure shows different stimuli that induce various membrane and cytoplasmic proteins which then positively or negatively regulate other proteins. PhoPQ two-component system is activated (green arrow) by cationic antimicrobial peptides (CAMP), low $\mathrm{Mg}^{2+}$, low $\mathrm{pH}$, low $\mathrm{MgCl}^{2+}, \mathrm{low} \mathrm{CaCl}^{2+}$, extracellular DNA and mutations (denoted by red-colored star symbols) in $p h o P / p h o Q$. PhoPQ controls many genes required for LPS modification and alteration of the cell surface. These include the $\operatorname{pmrD}, \operatorname{pag} L, \operatorname{mgrR}, \operatorname{mgtA}, \operatorname{ugtL}$, virK, mig-14, pgtE, ydeI, pagP, lpxO and cps operon. The activation of this two-component system mediates acylation, deacylation and hydroxylation of lipid A regulated by genes encoding the enzymes Pag, PagL and LpxO, respectively. The expression of EptB (phosphoethanolamine transferase) is suppressed (red line) with MgrR, while EptB is associated with the phosphoethanolamine addition to 3-deoxy-Dmanno-oct-2-ulosonic acid (KDO). The lipid A is further modified by $m g t A$. Transcription of the genes $u g t L$, virK, $m i g$ - 14 and $p g t E$ participate in the mediation of polymyxin resistance and have functions associated with the alteration of the bacterial envelope. PhoPQ, as well as PmrAB, are required for the induction of $y d e I$ which contributes to polymyxin resistance through its interaction with an outer membrane porin $\mathrm{OmpD} / \mathrm{NmpC}$. Additional $c p s$ genes are required for synthesis of polysaccharide capsule and be involved in the phosphorylation of Ugd. By contrast, MgrB, BrlR and MicA apply negative feedback to the PhoPQ regulatory system. With the help of PmrD, CbrA and in the presence of CAMP, $\mathrm{Zn}^{2+}$, high $\mathrm{Fe}^{3+}$, low $\mathrm{pH}, \mathrm{Al}^{3+}$, vanadate, low $\mathrm{MgCl}^{2+}$, low $\mathrm{CaCl}^{2+}$ and extracellular DNA, transcription of PmrA-activated gene is induced by PmrAB system. PmrA-P activates transcription of LPS modification loci (i.e., wzz, naxD, cptA, pmrG, pmrR, ydeI, pmrC, and arnBCADTEF-ugd), except for lpxR, which is downregulated. Synthesis of the O-antigen is controlled by the wzz gene products. The NaxD and LpxR proteins are responsible for the deacylation of lipid A. However, MicF causes downregulation of LpxR synthesis, which is associated with deacylation of lipid A. The initiation of transcription of $l p x R$ may play a role in resistance to polymyxin, but its effect on the resistance has not yet been demonstrated. Further, the CptA protein and PmrG regulate the phosphorylation modification of heptose-I and heptose-II residues on the LPS core, respectively. Likewise, PmrR inhibits the activity of $l p x T$, which phosphorylates lipid A. Additionally, phosphorylated PmrA activates the arnBCADTEF-ugd and $p m r C$ genes, which modify LPS with 4-amino-4-deoxy-Larabinose (L-Ara4N) and lipid A with PEtn, respectively. Moreover, also mutations in $p m r A, p m r B$ and $c r r B$ genes through CrrC result in the activation of PmrA, which subsequently upregulates $p m r C$ and $\operatorname{arnBCADTEF-ugd}$. Alternatively, pmrC (eptA) can be activated by the ColRS two-component system, mutations in pmrAB or acidic growth conditions. ParR can be phosphorylated and 
controls its regulatory network in response to polymyxins and indolicidin. The ParRS system controls the expression of the porin (oprD), efflux (mexXY-oprM) and LPS modifying (arnBCADTEF-ugd, pmrAB operon). In addition, the arnBCADTEF-ugd can be activated via mutations in the pmrAB and parRS, etk (required for phosphorylation of Ugd), acidic growth conditions and other two-component systems, such as CprRS and CbrAB. However, expression of arnBCADTEF-ugd is negatively regulated by ColRS. CprRS is able to sense CP-26/-28/-29, polymyxins, Bac2A, CRAMP, indolicidin, HHC36, IDR-1018 and HH17. Further, Zn ${ }^{2+}$ and nitrogen/carbon sources trigger activation of ColRS and CbrAB, respectively, whereas the CbrA protein is also able to induce the oprH-phoPQ operon. Mutations within genes $l p x A C D$ and $l p t D$ involved in lipid A biosynthesis and assembly of LPS in the outer leaflet of the outer membrane are associated with LPS loss, rescpectively. These results show that polycationic antibiotics (colistin and polymyxin B) and other factors are capable of promoting the expression of different two-component system and the mexXY operon and coordinated downregulation of the $\operatorname{pr} D$ gene by activation of ParRS, which ultimately leads to multiple resistance. In our model LPS represents the major barrier to binding of polymyxins. Further, siaD, ompA, cps, kpnEF, phoPQ and $r c s$, participate in capsule production leading to an increase in polymyxin resistance. Catalase, KatA, and other detoxifying enzymes, SodB and SodC, are also associated with resistance to polymyxin through their antioxidant defense mechanisms, whereas the $y i e M$ gene can mediate resistance by inducing outer membrane vesiculation. Recently, a mobile phosphoethanolamine transferase gene, $m c r$, has been associated with colistin resistance. It indicates resistance due to modifications of the phosphate groups of lipid A in LPS.

bilization of membrane structure (reduction of membane fluidity) ( ref. $^{28}$ ).

\section{Surface and membrane remodelling}

Further cell wall alterations, particularly capsule production, changes in membrane composition, and LOS and LPS modifications, are related with the development of polymyxin resistance. It has been found that the production of capsular polysaccharide or capsule is responsible for resistance to polymyxin B in Neisseria meningitidis and $K$. pneumoniae. However, synthesis of polysaccharide capsule was regulated by siaD, OmpA and cps operon (wca) (ref. ${ }^{29-31}$ ). In this context, further study showed that PhoPQ is necessary for polymyxin B-triggered induction of cps operon in $K$. pneumoniae ${ }^{20}$. Interestingly, a multidrug efflux pump $k p n E F$ mutant showed a defect in capsular synthesis, indicating the direct involvement of KpnEF in capsule synthesis ${ }^{32}$. In addition, Rcs system (regulator of capsule synthesis) has been described to contribute to polymyxin B resistance in $S$. enterica for its role in regulating the expression of gene $y d e I\left(\right.$ ref. $\left.^{33,34}\right)$. Furthermore, it has been found that the expression of cps operon and ugd is regulated by the Rcs system ${ }^{34}$, whereas the strain with expressed RcsA transcriptional regulator is able to synthesize colanic acid ${ }^{35}$. The effect of the capsules in this case lies in increasing electrostatic interaction between capsule polysaccharides and polymyxins, the binding of the cationic polymyxins to the anionic polysaccharides of the capsule, thereby reducing the amount of peptides reaching the bacterial surface and reducing its bactericidal activity $^{36}$.

With respect to the changes in membrane composition, $\operatorname{vir} B$ has been implicated in cationic peptide polymyxin B resistance of Brucella ovis and Brucella melitensis through a mechanism that involves modification of cell surface which is achieved by the down-regulation of Omp25/Omp31 family and regulation of type IV secretion system ${ }^{37-39}$. Other genes such as $s u h B_{B c}$, bvrR/S twocomponent regulatory system, eps $C-N$, cgh (choloylglycine hydrolase), waaL, $r f b A$, vacJ and omp $W$, have been shown to contribute to polymyxin $\mathrm{B}$ or colistin resistance in many pathogens through alterations in the OM composi$\operatorname{tion}^{37,40-47}$. It has been found that various environmental signals such as high temperature, oxidative stress, or salicylate have an effect on the expression of porins through mic $F$ regulation ${ }^{48}$. MicF expression has been connected with downregulation of OM porin OmpF mRNA, which contributed to polymyxin B resistance in $S$. enterica ${ }^{49}$. In P. aeruginosa, it was found that the ParRS system affects polymyxin B and colistin resistance through down-regulation of the porin (OprD) (ref. ${ }^{10,12}$ ). In this context, it has been demonstrated that oligosaccharide/oligonucleotide binding-fold (OB-fold) proteins YdeI (OmdA) and YgiW (VisP), and porins [OmpD (NmpC in E. coli) and $\mathrm{OmpF}$ ] contribute to polymyxin B resistance in $S$. enterica by cell wall remodelling (interaction between general porins and OB-fold proteins blocks antibiotic entry) or it is also likely that increase antibiotic export ${ }^{33,50}$. However, the main feature of general porins, for example OmpF in $E$. coli, is to create a size-selective defined channel for the diffusion of hydrophilic molecules with a certain priority of molecules with charges which are the opposite of the amino acids that line the channels ${ }^{51}$. It has been also demonstrated that the pilMNOPQ operon encoding components of the type IV pilin secretion system in $N$. meningitidis contributes to polymyxin $\mathrm{B}$ resistance ${ }^{52}$. In addition, in $P$. aeruginosa, the small RNA-binding protein RsmA is associated with polymyxin B and colistin resistance through its involvement in the type three secretion system (TTSS) $\left(\right.$ ref. $\left.^{53}\right)$. It is believed that pilin secretion apparatus may be the entry gate for several structurally different antimicrobial agents. Moreover, the type III and IV pilin secretion system is involved in the regulation of the delivery of proteins or DNA through the bacterial cell envelope. Further, a mechanism has been described by which B. melitensis maintains a low level of phosphatidylethanolamine in the cell wall by expression of the BveA phospholipase A1 enzyme ${ }^{54}$. This property of the cell envelope contributes to polymyxin resistance as well as to persistence in the infected host. It has been suggested that BveA is important because it is capable of preventing the formation of pore-like structure and the permeabilization of the cytoplasmic membrane by polymyxin.

Recently, Cheah et al. have described perturbation of the membrane in polymyxin-treated $A$. baumannii through over-expression of protein complexes involved in mem- 
brane homeostasis, namely Lol lipoprotein transport complex and the TolQRA transmembrane complex ${ }^{55}$. This supports findings related to the reduced integrity and barrier function of the remodelled OM in A. baumannii treated with polymyxin. Further, the genes cas 9 , $\operatorname{tracr} R N A$ and scaRNA in Francisella novicida promote enhanced envelope integrity through the regulation of bacterial lipoproteins and were necessary for polymyxin $\mathrm{B}$ resistance ${ }^{56}$.

In view of LPS and LOS changes, inactivation of the genes ( $\operatorname{spg} M$, pgm, hldA and hldD) showed changes in LPS and this correlated with increased susceptibility to polymyxin B in Stenotrophomonas maltophilia, Vibrio fischeri, Burkholderia cenocepacia, E. coli and Proteus mirabilis, respectively ${ }^{38,57-60}$. HldA and HldD gene products have been shown to play a role in the modification of heptose sugars. However, spgM and pgm (phosphoglucomutase) genes have been demonstrated to play a role in catabolism of galactose and in the promotion of UDP-glucose production in $E$. coli, and LPS and alginate biosynthesis as a homologue of the $\operatorname{alg} C$ gene in $P$. aeruginosa, respectively. Moreover, OM protein OprH has been reported to affect resistance to antimicrobial peptide polymyxin $\mathrm{B}$ in $P$. aeruginosa ${ }^{61,62}$. Polymyxin B resistance resulted from LPS alteration (interaction of $\mathrm{OprH}$ with divalent cation-binding sites of LPSs). Further, expression of the cj1136 gene (putative galactosyltransferase), involved in LOS biosynthesis, is associated with in Campylobacter jejuni polymyxin B resistance ${ }^{63}$. In this context, insertional inactivation of genes involved in synthesis and extension of LOS, namely waaF, lgtF, galT, cstII and galU in $C$. jejuni, resulted in decreased resistance to polymyxin B (>15-fold reduction in MIC) (ref. $\left.{ }^{64,65}\right)$. Additionally, it has been described elsewhere that galU (involved in L-Ara4N biosynthesis) also in other species such as $P$. mirabilis ${ }^{66}$, and Yersinia pestis ${ }^{67}$ contributes to resistance to polymyxin B. It was further reported that mutations in the genes of Haemophilus influenzae (lic1, lic $2 A$, lpsA, lgt $F$, ops $X$ ) also involved in LOS biosynthesis lead to increased susceptibility to polymyxin B (ref. ${ }^{68}$ ). FirA in E. coli and $S$. Typhimurium has also been shown to be important for lipid A biosynthesis and resistance to polymyxin B $\left(\right.$ ref $\left.^{69}\right)$. Interestingly, UDP-3-O-3-hydroxymyristoyl glucosamine $\mathrm{N}$-acyltransferase (LpxD) in higher copy number, a FirA homolog, was found in Pseudomonas putida strain HB3267 and may be responsible for higher resistance to polymyxin $\mathrm{B}$ than other strains ${ }^{70}$. Furthermore, in one study, it has been reported that other genes regulating, for example, biofilm formation or LPS and LOS modification (ie, lpxO) $\left(\right.$ ref. $\left.^{71}\right)$ correlate with increased resistance towards polymyxins, which are described in more detail elsewhere ${ }^{2}$.

It was also found that complete loss of LPS production by mutations in $\operatorname{lpxACD}$ which are involved in lipid A biosynthesis, exhibited a colistin-resistant phenotype in Acinetobacter baumannii ${ }^{72}$. In addition, a mutation in the OM protein, LptD, which allows the final transfer of the newly synthesized LPS, resulted in a complete loss of LPS and decreased susceptibility to polymyxin in $A$. baumannii ${ }^{73}$.

\section{Efflux and transport}

Several different types of multidrug efflux pumps in different pathogens have been shown to confer tolerance towards polymyxin B. For more informations see $^{2}$. Recently, implication of efflux transporter proteins (AdeABC and HlyD family) in polymyxin resistance in $A$. baumannii has been reported ${ }^{55}$. The AdeABC is homologous to the AcrABC and MexAB-OprM pumps. Further, relationship between TTSS via the RsmA protein and the expression of multidrug efflux (Mex) pumps has also been described in $P$. aeruginosa, whereas increased expression of MexCD-OprJ or MexEF-OprN was associated with decreased expression of the TTSS regulon ${ }^{74}$. Furthermore, it has been reported, that the potassium uptake protein in Vibrio vulnificus, TrkA, was responsible for resistance to polymyxin B ( ref. $^{75}$ ). Besides, it has been shown that the reaccumulation of $\mathrm{K}^{+}$by protamine-treated cells results in protease expression of PgtE, which in turn degrades protamine, thus preventing the death of bacteria ${ }^{76}$.

\section{Other polymyxin resistance determinants with known, unclear and unknown function}

In $A$. baumannii, some 35 genes have shown to influence colistin resistance. Identified genes have been shown to play roles in the regulation of OM proteins, chaperones, protein biosynthesis factors, and metabolic enzymes (putative role in loss of biological fitness) ( ref. $^{77}$ ). Furthemore, it was found that additional 30 genes in $A$. baumannii were involved in resistance to colistin. These were identified to be involved in amino acid transport, lipid and phosphate metabolism (pathways and systems associated with osmotolerance), protein folding, and cell envelope biosynthesis ${ }^{3}$. In K. pneumoniae, in addition to the new two-component system CrrAB characterized by the regulation of colistin resistance through the activation of PmrAB, other genes were also transcriptionally upregulated [genes of cation transport/membrane integrity/efflux transporters $(\operatorname{mac} A B)]$ and have been linked with LPS modification, cation transport, maintenance of membrane integrity and unknown functions ${ }^{78}$. In Saccharomyces cerevisiae, pbs 2 gene was involved in resistance to polymyxin B when overexpressed. However, Pbs2 was found to encode a predicted protein kinase that plays a role in osmoregulation and thus affects the plasma membrane $^{79}$. In addition, it has been found that several genes in $V$. cholearae, including $v c 2728$ ( $g s p I), v c 2731$ (gspF), $v c 2732$ (gspE), vc0212 (lpxN), vc0224, vc0239, vc1981, associated with type II secretion system, LPS biosynthesis and modification, and unknown functions, were involved in resistance to polymyxin ${ }^{80}$. Also, it has been previously shown that Sip (silica-induced protein) involved in the increase of robustness of the cell surface of Thermus thermophilus helps to protect against peptide antibiotics like polymyxin B ( ref. $^{81}$ ). Interestingly, Manning and Kuehn revealed that hyper-vesiculating yie $M$ mutant was able to confer polymyxin B and colistin resistance to $E$. coli by induction of OM vesiculation ${ }^{82}$. It is also worth mentioning that pilus structural subunit PilB of $S$. agalactiae has been demonstrated to confer polymyxin B resistance and PilB 
contributed to binding of polymyxin $\mathrm{B}$, thereby preventing its interaction with the cell membrane ${ }^{83}$. In this context, type IV pili of $P$. aeruginosa have been shown to be important for resistance to colistin with regulation of motility and development of mushroom caps ${ }^{84}$. Additionally, some PhoP/PhoQ-regulated genes, namely ugtL, virK, mig-14 and pgtE, have been shown to contribute polymyxin B and/or CAMP resistance in S. enterica, based on potential inhibition of polymyxin binding ${ }^{85-87}$. However, UgtL has been also described to be involved in dephosphorylation of lipid A (ref. ${ }^{88}$ ). So far, it is still unknown whether this protein functions as an enzyme or as a regulator of the reaction. In addition, genes for the synthesis of putrescine and YceI, found to act as infochemicals, have been recently discovered to mediate polymyxin $B$ resistance in B. cenocepacia, most likely by sequestering the antibiotic $^{89}$. Another study has reported that mutants of the yejABEF operon, genes encoding putative ATP-binding cassette $(A B C)$ transporter, were found to be susceptible to polymyxin B (ref. ${ }^{90,91}$ ). It has been suggested that the transporter system encoded by the yej operon may be involved in virulence regulation in Brucella and may also be involved in antimicrobial peptides neutralization, similar to the transporter system encoded by the Salmonella yej operon. Furthermore, it was reported that acidic growth conditions were associated with polymyxin resistance and was mediated by transcriptional activity of genes $(y j d B /$ pmrC/pagB and pmrF) (ref. ${ }^{92,93}$ ). In another study, it has been reported that the transfer of bacteria to a mildly acidic environment $(\mathrm{pH} 5.8)$ resulted in the decrease of LpxT activity and strong induction of the addition of L-Ara4N and PEtn (ref. ${ }^{94}$ ). It is also worth mentioning that lack of magnesium, phosphate and iron ions have all been reported to lead to resistance to antimicrobial peptide polymyxin B (ref. ${ }^{61,95,96}$ ). In this context, it has previously been shown that expression of the etk (required for phosphorylation of Ugd) during cultivation of $E$. coli was stimulated with low $\mathrm{pH}$, low concentrations of magnesium and iron ions ${ }^{97}$. In addition, several genes have been implicated in the resistance towards polymyxin B in Yersinia enterocolitica and Yersinia pseudotuberculosis strains, namely, YPTB0331-0332-0333, likely through the ferric uptake regulation ${ }^{95}$. Interestingly, the presence of extracellular DNA also has been shown to contribute to colistin and polymyxin B resistance in S. Typhimurium and $P$. aeruginosa by activation of PhoPQ and PmrAB systems ${ }^{98,99}$. Last but not least, additional determinants associated with polymyxin resistance are described in $\left(\right.$ ref. $\left.^{2}\right)$.

Regarding genes with unclear function, there are some genes that have been differently regulated in colistin-resistant strains of $P$. aeruginosa including PA1199, PA2583, PA5548, PA2928 probably participating in LPS biosynthesis as well as non-LPS-mediated genes including PA1980 (eraR), PA5447 (wbpZ), PA4541 and PA1938 (ref. ${ }^{100}$ ). Further, it has been previously reported that $P$. aeruginosa genes [PA0401, pyrB, pdxB, sucC, tpiA, aroB, pyrD, $m p l$, hypothetical protein ( $r m l D$ homolog), ampR, lptC, amgS, galU, lptC, wapR, and $s s g$ ] play a role in polymyxin $B$ resistance given their potential regulatory function, role in metabolic pathways, LPS biosynthesis and unknown functions $^{101}$. Moreover, gene $c g t$ has been reported to be associated with colistin resistance in Helicobacter pylori, suggesting its potential involvement in lipid A modification $^{102}$. Moreover, DNA sequence analysis of the mutagenized loci, JSG945 (putative O-acetyltransferase, which is essential for the addition of aminoarabinose to lipid A), JSG946, JSG947 (putative ATP synthase), and JSG948 (putative sap loci), revealed the role of these genes in conferring resistance to polymyxin B in P. mirabilis ${ }^{103}$. It has also been demonstrated in $B$. ovis that resistance to the polymyxin $\mathrm{B}$ affects the $b a c A$ gene, probably by altering the structure of the bacterial envelope ${ }^{38}$. Furthermore, it was found that a putative pgm gene (BRA 0348) in Brucella suis and surA, tolB, and gnd genes in S. enterica were shown to be necessary for polymyxin resistance, probably due to its putative OM modification (LPS structure or from destabilization of the membrane) (ref. ${ }^{43,104}$ ). In this context, it has been found that periplasmic chaperone SurA in E. coli plays an important role in transporting the LptD to the OM assembly site ${ }^{105}$. Gattis et al. have been shown that three genes $k d n A / k d n B$ and fop $C$ contribute to polymyxin resistance in many pathogens because of its potential role in OM integrity ${ }^{106,107}$. From E coli and Streptococcus pyogenes mutant screening, a number of other genes (PstA/C/S, EbsA, TopA, FtsH, GdpP, FabT, YfmH, AgaS, ManL/N, ClpX, DeoB, Hpt, TilS, Gmk, NanH, GuaA, NupP, PtsI, LuxR, Fba) have been identified to be required for resistance to polymyxin. These genes encode proteins with potential role in OM integrity and disruption of ExPortal integrity and thereby contribute to polymyxin resistance ${ }^{108,109}$. In a previous study, it was shown that asmA, pbgP, $m g l B, g l p Q$-like, feoC, $h f l c$, pitA genes have been implicated in resistance to polymyxin $\mathrm{B}$ in $Y$. pestis. This resistance was linked with putative modification of molecules or molecular composition of the bacterial OM (ref. ${ }^{110}$ ). Further, periplasmic chaperone proteins, Spy, ZraP, CpxP, have been reported to play a role in resistance against polymyxin B in $S$. enterica which could be affected by the envelope stress response regulation, while ZraP has been proposed to act to repress the expression of two-component system ZraSR (ref. ${ }^{111}$ ). Interestingly, $\sigma^{\mathrm{E}}$-controlled small non-coding RNAs, MicA and RybB, were activated in S. enterica treated cells with polymyxin B and are likely to facilitate the remodelling of the OM by reduction of the expression OM proteins (MicA represses OmpA synthesis, while RybB inhibits both OmpC and OmpW expression) (ref. ${ }^{49}$ ). Moreover, MicA has been shown to be a feedback inhibitor of the phoPQ system of $E$. coli ${ }^{112}$. Further, the involvement of $\operatorname{sodB}$ (A1S_2343) and sodC genes in colistin resistance have been observed in $A$. baumannii, probably by detoxifying reactive oxygen species ${ }^{113,114}$. In this context, katA (catalase) was found to confer resistance to polymyxin B in $S$. aureus. The resistance to polymyxin B was derived from its antioxidative defense mechanisms ${ }^{28}$.

Furthermore, other genes, such as $\operatorname{rpoE}\left(\sigma^{\mathrm{E}}\right)$, BCAL2831, mucD, ispH ${ }_{B C A L 2710}$ (lytB), hpnJ, have been found to be related to polymyxin $\mathrm{B}$ resistance in $B$. cenocepacia through unknown mechanisms, with the exception of mechanisms that do not contribute to weak binding of 
polymyxin to $B$. cenocepcia cells or to poor permeabilization of the outer membrane. However, the gene ispH (isoprenoid synthesis) increased OM stability and reduced molecular permeability ${ }^{26,115}$. Furthermore, $Y$. pestis resistance to cationic peptide polymyxin B is due to changes in unidentified surface structures mediated by regulation of $\operatorname{pgm} A$ activity ${ }^{116}$. In addition, grxD mutant, a gene with unknown function, showed increased susceptibility to polymyxin B in $P$. aeruginosa ${ }^{117}$.

\section{CONCLUSION}

Polymyxins are powerful bactericidal antibiotics that are effective against gram-negative bacteria. Despite their possible negative effect on the nerves and the kidneys in humans, they represent the last line of defense against persistent multidrug-resistant infections. Research into polymyxin resistance has led to the elucidation of many mechanisms and pathways that in some way affect resistance itself. In this report, we have tried to approach all the mechanisms of resistance described so far, although there are still many unknown and unresolved mechanisms of resistance. Still, we hope that a deeper understanding of the resistance mechanism will improve the ability to design and develop more efficient and toxic derivatives of polymyxins. It is also worth mentioning the discovery of the plasmid-mediated colistin resistance genes, $\mathrm{mcr}$, and therefore we can assume that other plasmid-mediated genes will be described in the near future. The primers described in our study may be used for detection of $\mathrm{mcr}$ genes and their variants, which could ultimately limit the dissemination of colistin-resistant bacteria.

\section{ABBREVIATIONS}

ABC, ATP-binding cassette; CAMP, cationic antimicrobial peptides; L-Ara4N, 4-amino-4-deoxy-L-arabinose; LPS, lipopolysaccharide; PEtn, phosphoethanolamine; OM, outer membrane; TCSs, two-component systems; TTSS, type three secretion system.

\section{Search strategy and selection criteria}

We searched Google Scholar for articles published in English between 1970 and December 2018 using the keywords "polymyxin resistance”, "polymyxin B”, "colistin”, "bacteria”, "genes”, "colistin-resistant”, "LPS” and " $m c r$ ". Bibliographies of all appropriate studies have been reviewed to identify other eligible studies.

Acknowledgement: This publication was supported by the National Sustainability Program (LO1304), by the Palacky University Internal Financial Support, project no. IGA_LF_2018_019 and "Increasing internationalization at the Faculty of Medicine and Dentistry, Palacky University Olomouc” (SPP 210015017).

Author contributions: PM: wrote the manuscript and conducted the literature review. MK: provided broad ideas and structure, as well as revisions.
Conflict of interest statement: The authors declare no conflict of interest.

\section{REFERENCES}

1. Olaitan AO, Morand S, Rolain JM. Emergence of colistin-resistant bacteria in humans without colistin usage: a new worry and cause for vigilance. Int J Antimicrob Ag 2016;47(1):1-3.

2. Trimble MJ, Mlynarcik P, Kolar M, Hancock RE. Polymyxin: Alternative Mechanisms of Action and Resistance. Cold Spring Harb Perspect Med 2016;6(10).

3. Hood MI, Becker KW, Roux CM, Dunman PM, Skaar EP. genetic determinants of intrinsic colistin tolerance in Acinetobacter baumannii. Infect Immun 2013;81(2):542-51.

4. Fernandez L, Jenssen H, Bains M, Wiegand I, Gooderham WJ, Hancock RE. The two-component system CprRS senses cationic peptides and triggers adaptive resistance in Pseudomonas aeruginosa independently of ParRS. Antimicrob Agents Chemother 2012;56(12):6212-22.

5. Liu YY, Wang Y, Walsh TR, Yi LX, Zhang R, Spencer J, Doi Y, Tian GB, Dong BL, Huang XH, Yu LF, Gu DX, Ren HW, Chen XJ, Lv LC, He DD, Zhou HW, Liang ZS, Liu JH, Shen JZ. Emergence of plasmid-mediated colistin resistance mechanism MCR-1 in animals and human beings in China: a microbiological and molecular biological study. Lancet Infectious Diseases 2016;16(2):161-8.

6. McPhee JB, Lewenza S, Hancock RE. Cationic antimicrobial peptides activate a two-component regulatory system, PmrA-PmrB, that regulates resistance to polymyxin $B$ and cationic antimicrobial peptides in Pseudomonas aeruginosa. Mol Microbiol 2003;50(1):205-17.

7. Moon K, Gottesman S. A PhoQ/P-regulated small RNA regulates sensitivity of Escherichia coli to antimicrobial peptides. Mol Microbiol 2009;74(6):1314-30.

8. Kato A, Groisman EA. Connecting two-component regulatory systems by a protein that protects a response regulator from dephosphorylation by its cognate sensor. Genes Dev 2004;18(18):2302-13.

9. Cheng YH, Lin TL, Lin YT, Wang JT. Amino Acid Substitutions of CrrB Responsible for Resistance to Colistin through CrrC in Klebsiella pneumoniae. Antimicrob Agents Chemother 2016;60(6):3709-16.

10. Muller $C$, Plesiat $P$, Jeannot $K$. A two-component regulatory system interconnects resistance to polymyxins, aminoglycosides, fluoroquinolones, and beta-lactams in Pseudomonas aeruginosa. Antimicrob Agents Chemother 2011;55(3):1211-21.

11. Gutu AD, Sgambati N, Strasbourger P, Brannon MK, Jacobs MA, Haugen E, Kaul RK, Johansen HK, Hoiby N, Moskowitz SM. Polymyxin resistance of Pseudomonas aeruginosa phoQ mutants is dependent on additional two-component regulatory systems. Antimicrob Agents Chemother 2013;57(5):2204-15.

12. Fernandez L, Gooderham WJ, Bains M, McPhee JB, Wiegand I, Hancock REW. Adaptive resistance to the "last hope" antibiotics polymyxin $B$ and colistin in Pseudomonas aeruginosa is mediated by the novel two-component regulatory system ParR-ParS. Antimicrob Agents Chemother 2010;54(8):3372-82.

13. Herbert S, Bera A, Nerz C, Kraus D, Peschel A, Goerke C, Meehl M, Cheung A, Gotz F. Molecular basis of resistance to muramidase and cationic antimicrobial peptide activity of lysozyme in staphylococci. PLoS Pathog 2007;3(7):e102.

14. Taneja NK, Ganguly T, Bakaletz LO, Nelson KJ, Dubey P, Poole LB, Deora R. D-alanine modification of a protease-susceptible outer membrane component by the Bordetella pertussis dra locus promotes resistance to antimicrobial peptides and polymorphonuclear leukocyte-mediated killing. J Bacteriol 2013;195(22):5102-11.

15. Abachin E, Poyart C, Pellegrini E, Milohanic E, Fiedler F, Berche P, Trieu-Cuot P. Formation of D-alanyl-lipoteichoic acid is required for adhesion and virulence of Listeria monocytogenes. Mol Microbiol 2002;43(1):1-14.

16. McCormick NE, Halperin SA, Lee SF. Regulation of D-alanylation of lipoteichoic acid in Streptococcus gordonii. Microbiology 2011;157(Pt 8):2248-56.

17. Mazda Y, Kawada-Matsuo M, Kanbara K, Oogai Y, Shibata Y, Yamashita Y, Miyawaki S, Komatsuzawa H. Association of CiaRH with resistance of Streptococcus mutans to antimicrobial peptides in biofilms. Mol Oral Microbiol 2012;27(2):124-35.

18. Quach D, van Sorge NM, Kristian SA, Bryan JD, Shelver DW, Doran 
KS. The CiaR response regulator in group B Streptococcus promotes intracellular survival and resistance to innate immune defenses. J Bacteriol 2009;191(7):2023-32.

19. Su J-H, Chung Y-C, Lee H-C, Tseng IC, Chang M-C. Ferrous ironbinding protein Omb of Salmonella enterica serovar Choleraesuis promotes resistance to hydrophobic antibiotics and contributes to its virulence. Microbiology (Reading, England) 2009;155(Pt 7):236574.

20. Llobet E, Campos MA, Gimenez P, Moranta D, Bengoechea JA. Analysis of the networks controlling the antimicrobial-peptidedependent induction of Klebsiella pneumoniae virulence factors. Infect Immun 2011;79(9):3718-32.

21. Robey M, O'Connell W, Cianciotto NP. Identification of Legionella pneumophila rcp, a pagP-like gene that confers resistance to cationic antimicrobial peptides and promotes intracellular infection. Infect Immun 2001;69(7):4276-86.

22. Clements A, Tull D, Jenney AW, Farn JL, Kim SH, Bishop RE, McPhee JB, Hancock RE, Hartland EL, Pearse MJ, Wijburg OL, Jackson DC, McConville MJ, Strugnell RA. Secondary acylation of Klebsiella pneumoniae lipopolysaccharide contributes to sensitivity to antibacterial peptides. J Biol Chem 2007;282(21):15569-77.

23. Matson JS, Yoo HJ, Hakansson K, Dirita VJ. Polymyxin B resistance in El Tor Vibrio cholerae requires lipid acylation catalyzed by MsbB. J Bacteriol 2010;192(8):2044-52.

24. Murray SR, Ernst RK, Bermudes D, Miller SI, Low KB. pmrA(Con) confers pmrHFIJKL-dependent EGTA and polymyxin resistance on msbB Salmonella by decorating lipid A with phosphoethanolamine. J Bacteriol 2007;189(14):5161-9.

25. Tran AX, Lester ME, Stead CM, Raetz CR, Maskell DJ, McGrath SC, Cotter RJ, Trent MS. Resistance to the antimicrobial peptide polymyxin requires myristoylation of Escherichia coli and Salmonella typhimurium lipid A. J Biol Chem 2005;280(31):28186-94.

26. Malott RJ, Steen-Kinnaird BR, Lee TD, Speert DP. Identification of hopanoid biosynthesis genes involved in polymyxin resistance in Burkholderia multivorans. Antimicrob Agents Chemother 2012;56(1):464-71.

27. Rezanka T, Siristova L, Melzoch K, Sigler K. Hopanoids in Bacteria and Cyanobacteria - Their Role in Cellular Biochemistry and Physiology, Analysis and Occurrence. Mini-Rev Org Chem 2010;7(4):300-13.

28. Antonic V, Stojadinovic A, Zhang B, Izadjoo MJ, Alavi M. Pseudomonas aeruginosa induces pigment production and enhances virulence in a white phenotypic variant of Staphylococcus aureus. Infect Drug Resist 2013;6:175-86.

29. Campos MA, Vargas MA, Regueiro V, Llompart CM, Alberti S, Bengoechea JA. Capsule polysaccharide mediates bacterial resistance to antimicrobial peptides. Infect Immun 2004;72(12):7107-14.

30. Llobet E, March C, Gimenez P, Bengoechea JA. Klebsiella pneumoniae OmpA confers resistance to antimicrobial peptides. Antimicrob Agents Chemother 2009;53(1):298-302.

31. Spinosa MR, Progida C, Tala A, Cogli L, Alifano P, Bucci C. The Neisseria meningitidis capsule is important for intracellular survival in human cells. Infect Immun 2007;75(7):3594-603.

32. Srinivasan VB, Singh BB, Priyadarshi N, Chauhan NK, Rajamohan G. Role of novel multidrug efflux pump involved in drug resistance in Klebsiella pneumoniae. PLoS One 2014;9(5):e96288.

33. Pilonieta MC, Erickson KD, Ernst RK, Detweiler CS. A protein important for antimicrobial peptide resistance, Ydel/OmdA, is in the periplasm and interacts with $\mathrm{OmpD} / \mathrm{NmpC}$. J Bacteriol 2009;191(23):7243-52.

34. Mouslim C, Groisman EA. Control of the Salmonella ugd gene by three two-component regulatory systems. Mol Microbiol 2003:47(2):335-44.

35. Obadia B, Lacour S, Doublet P, Baubichon-Cortay H, Cozzone AJ, Grangeasse C. Influence of tyrosine-kinase Wzc activity on colanic acid production in Escherichia coli K12 cells. J Mol Biol 2007;367(1):42-53.

36. Llobet E, Tomas JM, Bengoechea JA. Capsule polysaccharide is a bacterial decoy for antimicrobial peptides. Microbiol-Sgm 2008; 154:3877-86.

37. Marchesini MI, Connolly J, Delpino MV, Baldi PC, Mujer CV, DelVecchio VG, Comerci DJ. Brucella abortus choloylglycine hydrolase affects cell envelope composition and host cell internalization. PloS one 2011;6(12):e28480.

38. Martin-Martin Al, Sancho P, de Miguel MJ, Fernandez-Lago L,
Vizcaino N. Quorum-sensing and BvrR/BvrS regulation, the type IV secretion system, cyclic glucans, and BacA in the virulence of Brucella ovis: similarities to and differences from smooth brucellae. Infect immun 2012;80(5):1783-93.

39. Wang Y, Chen Z, Qiao F, Zhong Z, Xu J, Wang Z, Du X, Qu Q, Yuan J, Jia $L$, Song $H$, Sun $Y$, Huang $L$. The type IV secretion system affects the expression of Omp25/Omp31 and the outer membrane properties of Brucella melitensis. FEMS microbiology letters 2010;303(1):92100.

40. Caro-Hernandez P, Fernandez-Lago L, de Miguel M-J, Martin-Martin Al, Cloeckaert A, Grillo M-J, Vizcaino N. Role of the Omp25/Omp31 family in outer membrane properties and virulence of Brucella ovis. Infect immun 2007;75(8):4050-61.

41. Guzman-Verri C, Manterola L, Sola-Landa A, Parra A, Cloeckaert A Garin J, Gorvel JP, Moriyon I, Moreno E, Lopez-Goni I. The two-component system BvrR/BvrS essential for Brucella abortus virulence regulates the expression of outer membrane proteins with counterparts in members of the Rhizobiaceae. Proc Natl Acad Sci U S A 2002;99(19):12375-80.

42. Chopra S, Ramkissoon K, Anderson DC. A systematic quantitative proteomic examination of multidrug resistance in Acinetobacter baumannii. J Proteomics 2013;84:17-39.

43. Liautard J, Ouahrani-Bettache S, Jubier-Maurin V, Lafont V, Kohler S, Liautard JP. Identification and isolation of Brucella suis virulence genes involved in resistance to the human innate immune system. Infect Immun 2007;75(11):5167-74.

44. Rosales-Reyes R, Saldias MS, Aubert DF, El-Halfawy OM, Valvano MA. The suhB gene of Burkholderia cenocepacia is required for protein secretion, biofilm formation, motility and polymyxin $B$ resistance. Microbiology (Reading, England) 2012;158(Pt 9):2315-24.

45. Sikora AE, Lybarger SR, Sandkvist M. Compromised outer membrane integrity in Vibrio cholerae Type II secretion mutants. J Bacteriol 2007;189(23):8484-95.

46. Sola-Landa A, Pizarro-Cerda J, Grillo MJ, Moreno E, Moriyon I, Blasco JM, Gorvel JP, Lopez-Goni I. A two-component regulatory system playing a critical role in plant pathogens and endosymbionts is present in Brucella abortus and controls cell invasion and virulence. Mol Microbiol 1998;29(1):125-38.

47. Sassera D, Comandatore F, Gaibani P, D'Auria G, Mariconti M, Landini MP, Sambri V, Marone P. Comparative genomics of closely related strains of Klebsiella pneumoniae reveals genes possibly involved in colistin resistance. Ann Microbiol 2014;64(2):887-90.

48. Dupont M, De E, Chollet R, Chevalier J, Pages JM. Enterobacter aerogenes OmpX, a cation-selective channel mar- and osmo-regulated. Febs Lett 2004;569(1-3):27-30.

49. Papenfort K, Pfeiffer V, Mika F, Lucchini S, Hinton JC, Vogel J. SigmaEdependent small RNAs of Salmonella respond to membrane stress by accelerating global omp mRNA decay. Mol Microbiol 2006;62(6):1674-88

50. Moreira CG, Herrera CM, Needham BD, Parker CT, Libby SJ, Fang FC, Trent MS, Sperandio V. Virulence and stress-related periplasmic protein (VisP) in bacterial/host associations. Proc Natl Acad Sci U S A 2013;110(4):1470-5.

51. Achouak W, Heulin T, Pages JM. Multiple facets of bacterial porins. Fems Microbiology Letters 2001;199(1):1-7.

52. Tzeng Y-L, Ambrose KD, Zughaier S, Zhou X, Miller YK, Shafer WM, Stephens DS. Cationic antimicrobial peptide resistance in Neisseria meningitidis. J Bacteriol 2005;187(15):5387-96.

53. Mulcahy H, O'Callaghan J, O'Grady EP, Adams C, O'Gara F. The posttranscriptional regulator RsmA plays a role in the interaction between Pseudomonas aeruginosa and human airway epithelial cells by positively regulating the type III secretion system. Infect Immun 2006;74(5):3012-5.

54. Kerrinnes T, Young BM, Leon C, Roux CM, Tran L, Atluri VL, Winter MG, Tsolis RM. Phospholipase A1 Modulates the Cell Envelope Phospholipid Content of Brucella melitensis, Contributing to Polymyxin Resistance and Pathogenicity. Antimicrob Agents Chemother 2015;59(11):6717-24.

55. Cheah SE, Johnson MD, Zhu Y, Tsuji BT, Forrest A, Bulitta JB, Boyce JD, Nation RL, Li J. Polymyxin Resistance in Acinetobacter baumannii: Genetic Mutations and Transcriptomic Changes in Response to Clinically Relevant Dosage Regimens. Sci Rep-Uk 2016;6.

56. Sampson TR, Napier BA, Schroeder MR, Louwen R, Zhao J, Chin C-Y, Ratner HK, Llewellyn AC, Jones CL, Laroui H, Merlin D, Zhou P, Endtz 
HP, Weiss DS. A CRISPR-Cas system enhances envelope integrity mediating antibiotic resistance and inflammasome evasion. Proc Natl Acad Sci U S A 2014;111(30):11163-8.

57. DeLoney CR, Bartley TM, Visick KL. Role for phosphoglucomutase in Vibrio fischeri-Euprymna scolopes symbiosis. J Bacterio 2002;184(18):5121-9.

58. Loutet SA, Flannagan RS, Kooi C, Sokol PA, Valvano MA. A complete lipopolysaccharide inner core oligosaccharide is required for resistance of Burkholderia cenocepacia to antimicrobial peptides and bacterial survival in vivo. J Bacteriol 2006;188(6):2073-80.

59. McKay GA, Woods DE, MacDonald KL, Poole K. Role of phosphoglucomutase of Stenotrophomonas maltophilia in lipopolysaccharide biosynthesis, virulence, and antibiotic resistance. Infect Immun 2003;71(6):3068-75.

60. Subashchandrabose S, Smith SN, Spurbeck RR, Kole MM, Mobley HLT. Genome-wide detection of fitness genes in uropathogenic Escherichia coli during systemic infection. PLoS pathogens 2013;9(12):e1003788.

61. Macfarlane EL, Kwasnicka A, Ochs MM, Hancock RE. PhoP-PhoQ homologues in Pseudomonas aeruginosa regulate expression of the outer-membrane protein OprH and polymyxin B resistance. Mol Microbiol 1999;34(2):305-16.

62. Young ML, Bains M, Bell A, Hancock RE. Role of Pseudomonas aeruginosa outer membrane protein OprH in polymyxin and gentamicin resistance: isolation of an OprH-deficient mutant by gene replacement techniques. Antimicrob Agents Chemother 1992;36(11):25668.

63. Javed MA, Cawthraw SA, Baig A, Li J, McNally A, Oldfield NJ, Newell DG, Manning G. Cj1136 is required for lipooligosaccharide biosynthesis, hyperinvasion, and chick colonization by Campylobacter jejuni. Infect limmun 2012;80(7):2361-70.

64. Naito M, Frirdich E, Fields JA, Pryjma M, Li J, Cameron A, Gilbert M, Thompson SA, Gaynor EC. Effects of sequential Campylobacter jejuni 81-176 lipooligosaccharide core truncations on biofilm formation, stress survival, and pathogenesis. J Bacteriol 2010;192(8):2182-92.

65. Lin J, Wang Y, Hoang KV. Systematic identification of genetic loci required for polymyxin resistance in Campylobacter jejuni using an efficient in vivo transposon mutagenesis system. Foodborne Pathog Dis 2009;6(2):173-85.

66. Jiang SS, Lin TY, Wang WB, Liu MC, Hsueh PR, Liaw SJ. Characterization of UDP-glucose dehydrogenase and UDP-glucose pyrophosphorylase mutants of Proteus mirabilis: defectiveness in polymyxin $B$ resistance, swarming, and virulence. Antimicrob Agents Chemother 2010;54(5):2000-9.

67. Klein KA, Fukuto HS, Pelletier M, Romanov G, Grabenstein JP, Palmer LE, Ernst R, Bliska JB. A transposon site hybridization screen identifies galU and wecBC as important for survival of Yersinia pestis in murine macrophages. J Bacteriol 2012;194(3):653-62.

68. Morey P, Viadas C, Euba B, Hood DW, Barberan M, Gil C, Grillo MJ, Bengoechea JA, Garmendia J. Relative contributions of Iipooligosaccharide inner and outer core modifications to nontypeable Haemophilus influenzae pathogenesis. Infect Immun 2013;81(11):4100-11.

69. Vaara M. Outer membrane permeability barrier to azithromycin clarithromycin, and roxithromycin in gram-negative enteric bacteria. Antimicrob Agents Chemother 1993;37(2):354-6.

70. Molina L, Udaondo Z, Duque E, Fernandez M, Molina-Santiago C, Roca A, Porcel M, de la Torre J, Segura A, Plesiat $P$, Jeannot K, Ramos $\mathrm{J}$-L. Antibiotic resistance determinants in a Pseudomonas putida strain isolated from a hospital. PloS one 2014;9(1):e81604.

71. Gibbons HS, Lin S, Cotter RJ, Raetz CR. Oxygen requirement for the biosynthesis of the S-2-hydroxymyristate moiety in Salmonella typhimurium lipid A. Function of $\mathrm{LpxO}$, A new Fe2+/alpha-ketoglutarate-dependent dioxygenase homologue. J Biol Chem 2000;275(42):32940-9.

72. Moffatt JH, Harper M, Harrison $P$, Hale JDF, Vinogradov E, Seemann T, Henry R, Crane B, St Michael F, Cox AD, Adler B, Nation RL, Li J, Boyce JD. Colistin resistance in Acinetobacter baumannii is mediated by complete loss of lipopolysaccharide production. Antimicrob Agents Chemother 2010;54(12):4971-7.

73. Bojkovic J, Richie DL, Six DA, Rath CM, Sawyer WS, Hu Q, Dean CR. Characterization of an Acinetobacter baumannii IptD Deletion Strain: Permeability Defects and Response to Inhibition of Lipopolysaccharide and Fatty Acid Biosynthesis. J Bacteriol 2015;198(4):731-41.
74. Linares JF, Lopez JA, Camafeita E, Albar JP, Rojo F, Martinez JL. Overexpression of the multidrug efflux pumps MexCD-OprJ and MexEF-OprN is associated with a reduction of type III secretion in Pseudomonas aeruginosa. J Bacteriol 2005;187(4):1384-91.

75. Chen Y-C, Chuang Y-C, Chang C-C, Jeang C-L, Chang M-C. A K+ yptake protein, TrkA, is required for serum, protamine, and polymyxin $B$ resistance in Vibrio vulnificus. Infect Immun 2004;72(2):629-36.

76. Stumpe S, Bakker EP. Requirement of a large K+-uptake capacity and of extracytoplasmic protease activity for protamine resistance of Escherichia coli. Arch Microbiol 1997;167(2/3):126-36.

77. Fernandez-Reyes M, Rodriguez-Falcon M, Chiva C, Pachon J, Andreu $D$, Rivas L. The cost of resistance to colistin in Acinetobacter baumannii: a proteomic perspective. Proteomics 2009;9(6):1632-45.

78. Wright MS, Suzuki Y, Jones MB, Marshall SH, Rudin SD, van Duin D, Kaye K, Jacobs MR, Bonomo RA, Adams MD. Genomic and transcriptomic analyses of colistin-resistant clinical isolates of Klebsiella pneumoniae reveal multiple pathways of resistance. Antimicrob Agents Chemother 2015;59(1):536-43.

79. Boguslawski G. PBS2, a yeast gene encoding a putative protein kinase, interacts with the RAS2 pathway and affects osmotic sensitivity of Saccharomyces cerevisiae. J Gen Microbiol 1992;138(11):2425-32.

80. Herrera CM, Crofts AA, Henderson JC, Pingali SC, Davies BW, Trent MS. The Vibrio cholerae VprA-VprB two-component system controls virulence through endotoxin modification. MBio 2014;5(6).

81. Iwai S, Doi K, Fujino Y, Nakazono T, Fukuda K, Motomura Y, Ogata S. Silica deposition and phenotypic changes to Thermus thermophilus cultivated in the presence of supersaturated silicia. Isme J 2010;4(6):809-16.

82. Manning AJ, Kuehn MJ. Contribution of bacterial outer membrane vesicles to innate bacterial defense. BMC Microbiol 2011;11:258.

83. Maisey HC, Quach D, Hensler ME, Liu GY, Gallo RL, Nizet V, Doran KS. A group $B$ streptococcal pilus protein promotes phagocyte resistance and systemic virulence. FASEB J 2008;22(6):1715-24.

84. Haagensen JAJ, Klausen M, Ernst RK, Miller SI, Folkesson A, TolkerNielsen T, Molin S. Differentiation and distribution of colistin- and sodium dodecyl sulfate-tolerant cells in Pseudomonas aeruginosa biofilms. J Bacteriol 2007;189(1):28-37.

85. Brodsky IE, Ernst RK, Miller SI, Falkow S. mig-14 is a Salmonella gene that plays a role in bacterial resistance to antimicrobial peptides. J Bacteriol 2002;184(12):3203-13.

86. Guina T, Yi EC, Wang H, Hackett M, Miller SI. A PhoP-regulated outer membrane protease of Salmonella enterica serovar typhimurium promotes resistance to alpha-helical antimicrobial peptides. J Bacteriol 2000;182(14):4077-86.

87. Navarre WW, Halsey TA, Walthers D, Frye J, McClelland M, Potter JL, Kenney LJ, Gunn JS, Fang FC, Libby SJ. Co-regulation of Salmonella enterica genes required for virulence and resistance to antimicrobial peptides by SlyA and PhoP/PhoQ. Mol Microbiol 2005;56(2):492-508.

88. Shi Y, Latifi T, Cromie MJ, Groisman EA. Transcriptional control of the antimicrobial peptide resistance ugtL gene by the Salmonella PhoP and SlyA regulatory proteins. J Biol Chem 2004;279(37):38618-25.

89. El-Halfawy OM, Valvano MA. Chemical communication of antibiotic resistance by a highly resistant subpopulation of bacterial cells. PloS one 2013;8(7):e68874.

90. Eswarappa SM, Panguluri KK, Hensel M, Chakravortty D. The yejABEF operon of Salmonella confers resistance to antimicrobial peptides and contributes to its virulence. Microbiology 2008;154(Pt 2):666-78.

91. Wang Z, Bie PF, Cheng J, Lu L, Cui BY, Wu QM. The ABC transporter YejABEF is required for resistance to antimicrobial peptides and the virulence of Brucella melitensis. Sci Rep-Uk 2016;6.

92. Groisman EA, Kayser J, Soncini FC. Regulation of polymyxin resistance and adaptation to low-Mg2+ environments. Journal of bacteriology 1997;179(22):7040-5.

93. Soncini FC, Groisman EA. Two-component regulatory systems can interact to process multiple environmental signals. J Bacteriol 1996;178(23):6796-801.

94. Herrera CM, Hankins JV, Trent MS. Activation of PmrA inhibits LpxTdependent phosphorylation of lipid A promoting resistance to antimicrobial peptides. Mol Microbiol 2010;76(6):1444-60.

95. Arafah S, Rosso M-L, Rehaume L, Hancock REW, Simonet M, Marceau M. An iron-regulated LysR-type element mediates antimicrobial peptide resistance and virulence in Yersinia pseudotuberculosis. Microbiology (Reading, England) 2009;155(Pt 7):2168-81.

96. Lewenza S, Falsafi R, Bains M, Rohs P, Stupak J, Sprott GD, Hancock REW. The olsA gene mediates the synthesis of an ornithine lipid in 
Pseudomonas aeruginosa during growth under phosphate-limiting conditions, but is not involved in antimicrobial peptide susceptibility. FEMS microbiology letters 2011;320(2):95-102.

97. Lacour S, Doublet P, Obadia B, Cozzone AJ, Grangeasse C. A novel role for protein-tyrosine kinase Etk from Escherichia coli K-12 related to polymyxin resistance. Res Microbiol 2006;157(7):637-41.

98. Johnson L, Horsman SR, Charron-Mazenod L, Turnbull AL, Mulcahy $\mathrm{H}$, Surette MG, Lewenza S. Extracellular DNA-induced antimicrobial peptide resistance in Salmonella enterica serovar Typhimurium. BMC Microbiol 2013;13:115.

99. Mulcahy H, Charron-Mazenod L, Lewenza S. Extracellular DNA chelates cations and induces antibiotic resistance in Pseudomonas aeruginosa biofilms. PLoS pathogens 2008;4(11):e1000213.

100. Lee JY, Na IY, Park YK, Ko KS. Genomic variations between colistinsusceptible and -resistant Pseudomonas aeruginosa clinical isolates and their effects on colistin resistance. J Antimicrob Chemother 2014;69(5):1248-56.

101. Fernandez L, Alvarez-Ortega C, Wiegand I, Olivares J, Kocincova D, Lam JS, Martinez JL, Hancock REW. Characterization of the polymyxin $B$ resistome of Pseudomonas aeruginosa. Antimicrob Agents Chemother 2013;57(1):110-9.

102. McGee DJ, George AE, Trainor EA, Horton KE, Hildebrandt E, Testerman TL. Cholesterol enhances Helicobacter pylori resistance to antibiotics and LL-37. Antimicrob Agents Chemother 2011;55(6):2897-904.

103. McCoy AJ, Liu H, Falla TJ, Gunn JS. Identification of Proteus mirabilis mutants with increased sensitivity to antimicrobial peptides. Antimicrob Agents Chemother 2001;45(7):2030-7.

104. Tamayo R, Ryan SS, McCoy AJ, Gunn JS. Identification and genetic characterization of PmrA-regulated genes and genes involved in polymyxin $B$ resistance in Salmonella enterica serovar typhimurium. Infect Immun 2002;70(12):6770-8.

105. Denoncin K, Vertommen D, Paek E, Collet JF. The protein-disulfide isomerase DsbC cooperates with SurA and DsbA in the as sembly of the essential beta-barrel protein LptD. J Biol Chem 2010;285(38):29425-33.

106. Gattis SG, Chung HS, Trent MS, Raetz CR. The origin of 8-amino-3,8dideoxy-D-manno-octulosonic acid (Kdo8N) in the lipopolysaccharide of Shewanella oneidensis. J Biol Chem 2013;288(13):9216-25.

107. Nallaparaju KC, Yu JJ, Rodriguez SA, Zogaj X, Manam S, Guentze MN, Seshu J, Murthy AK, Chambers JP, Klose KE, Arulanandam BP.
Evasion of IFN-gamma signaling by Francisella novicida is dependent upon Francisella outer membrane protein C. PLoS One 2011;6(3):e18201.

108. Lamarche MG, Dozois CM, Daigle F, Caza M, Curtiss R, 3rd, Dubreuil $J D$, Harel J. Inactivation of the pst system reduces the virulence of an avian pathogenic Escherichia coli 078 strain. Infect Immun 2005;73(7):4138-45.

109. Port GC, Vega LA, Nylander AB, Caparon MG. Streptococcus pyogenes polymyxin B-resistant mutants display enhanced ExPortal integrity. J Bacteriol 2014;196(14):2563-77.

110. Guo J, Nair MKM, Galvan EM, Liu S-L, Schifferli DM. Tn5AraOut mutagenesis for the identification of Yersinia pestis genes involved in resistance towards cationic antimicrobial peptides. Microbial pathogenesis 2011;51(3):121-32.

111. Appia-Ayme C, Hall A, Patrick E, Rajadurai S, Clarke TA, Rowley $\mathrm{G}$. ZraP is a periplasmic molecular chaperone and a repressor of the zinc-responsive two-component regulator ZraSR. Biochem J 2012;442(1):85-93.

112. Coornaert A, Lu A, Mandin P, Springer M, Gottesman S, Guillier M. MicA sRNA links the PhoP regulon to cell envelope stress. Mol Microbiol 2010;76(2):467-79.

113. Heindorf M, Kadari M, Heider C, Skiebe E, Wilharm G. Impact of Acinetobacter baumannii superoxide dismutase on motility, virulence, oxidative stress resistance and susceptibility to antibiotics. PloS one 2014;9(7):e101033.

114. Pournaras S, Poulou A, Dafopoulou K, Chabane YN, Kristo I, Makris D, Hardouin J, Cosette P, Tsakris A, De E. Growth retardation, reduced invasiveness, and impaired colistin-mediated cell death associated with colistin resistance development in Acinetobacter baumannii. Antimicrob Agents Chemother 2014;58(2):828-32.

115. Loutet SA, Mussen LE, Flannagan RS, Valvano MA. A two-tier model of polymyxin $B$ resistance in Burkholderia cenocepacia. Environ Microbiol Rep 2011;3(2):278-85.

116. Felek S, Muszynski A, Carlson RW, Tsang TM, Hinnebusch BJ, Krukonis ES. Phosphoglucomutase of Yersinia pestis is required for autoaggregation and polymyxin B resistance. Infect Immun 2010;78(3):1163-75.

117. Romsang A, Leesukon P, Duangnkern J, Vattanaviboon P, Mongkolsuk S. Mutation of the gene encoding monothiol glutaredoxin (GrxD) in Pseudomonas aeruginosa increases its susceptibility to polymyxins. Int J Antimicrob Agents 2015;45(3):314-8. 